\title{
Nutritional Risk Screening Tools in Hospitalised Children
}

\author{
Vesal Moeeni and Andrew S. Day
}

\author{
Department of Paediatrics, University of Otago (Christchurch), Christchurch, New Zealand
}

\begin{abstract}
In clinical practice, the assessment of nutritional status in children can be problematic. More than one indicator is often required: these may include anthropometric measurements, body compartment analysis and biochemical markers. The nutritional status of children at the time of admission to hospital can impact adversely on their hospital stay. Furthermore, children's medical conditions may also impact upon their nutrition during a hospital stay.

In recent years a number of Nutrition Risk Screening (NRS) tools have been developed and validated, with the goals of providing rapid assessment of children's risk of nutritional change during a hospitalisation. This article reviews the current NRS tools, considers their benefits and shortcomings and evaluates the potential roles of these tools.
\end{abstract}

Keywords: Nutrition, nutritional risk screening, weight, height, children, hospital.

\section{INTRODUCTION}

Children requiring hospitalisation are at higher risk for malnutrition, especially development of undernutrition [1]. The nutritional status of children also impacts upon the outcome of hospitalisation, leading potentially to increased disease-related morbidity and prolonged hospitalisation (and consequent increased costs) [2, 3]. Assessing the nutritional state of children at the time of admission to hospital is consequently an important part of their clinical evaluation.

Identification of the enhanced risk of developing malnutrition could facilitate the introduction of early and timely nutritional support and prevent the long-term impact of malnutrition on growth and development of these children. The use of tools to screen individuals at the time of admission promises to be able to direct resources to those at need. The article will focus upon the development and application of such tools for the assessment of children.

\section{NUTRITIONAL ASSESSMENT IN CHILDREN}

A complete clinical assessment of nutritional status includes several steps with review of medical and dietary history, physical examination including anthropometric and body composition measurements and possibly laboratory data [4]. Although complete nutritional assessment for each patient might be ideal, in practice this would be a lengthy and costly process.

\section{NUTRITIONAL STATUS OF CHILDREN ADMITTED TO HOSPITAL}

Malnutrition, particularly under-nutrition, is often described in children requiring hospital admission.

*Address corresponding to this author at the Department of Paediatrics, University of Otago, Christchurch, P.O. Box 4345, Christchurch, New Zealand; Tel: 64-3-3640747; Fax: 64-3-3640919; E-mail: andrew.day@otago.ac.nz
Generally low rates are reported in developed countries $[1,5]$. In contrast, much higher rates of under-nutrition are observed in developing countries. For example, $31.8 \%$ of 170 Turkish children [6] and $60 \%$ of a group of Thai children [7] were malnourished at admission.

During admission some patients lose weight, consequently increasing the risk of nutritional deterioration. In a French study of 296 patients, 65\% lost weight during their hospital stay [8]. Similarly, almost half of a group of 186 Brazilian children aged less than 5 years of age lost weight during their hospital stay [9]. In this cohort, the children recognised as malnourished at admission remained malnourished at discharge, while about $10 \%$ of well-nourished children also become mildly malnourished during their stay.

\section{INTERRELATIONSHIP BETWEEN NUTRITIONAL STATUS AND MEDICAL DISEASE}

Children with chronic disease or those with multiple diagnoses are more prone to malnutrition at admission and during their hospital stay. The rate of malnutrition of children with chronic disease was $42.8 \%$ in the above-mentioned German study [1]. Several other studies also document that malnourished patients stay longer in hospital than well-nourished patients $[8,10$, 11]. An Australian study has established malnutrition could add up to AUS $\$ 5.2$ million per year to hospital costs [2]. In addition, a British study demonstrated that the identification and treatment of malnutrition, along with the primary disease, could lead to savings of up to $£ 266$ million per annum, along with reduction of mortality rates by up to $50 \%$ in adult patients [12].

\section{NUTRITIONAL RISK SCREENING TOOLS FOR CHILDREN}

Over recent years, several paediatric NRS tools have been developed. These include the NRS tool, 
Table 1: Nutrition Risk Screening Tools Developed for Children

\begin{tabular}{|c|c|c|}
\hline TOOL & TARGET GROUP & REFERENCE \\
\hline \hline Nutritional Risk Score (NRS) Tool & Adult and paediatric patients & [13] \\
\hline [8] & $\begin{array}{c}\text { Paediatric patients } \\
\text { aged }>1 \text { month }\end{array}$ & [3] \\
\hline $\begin{array}{c}\text { Subjective Global Nutritional Assessment for children } \\
\text { (SGNA) }\end{array}$ & $\begin{array}{c}\text { Paediatric patients } \\
\text { aged 30 days-17.9 years }\end{array}$ & [17] \\
\hline $\begin{array}{c}\text { Screening Tool for Assessment of Malnutrition in } \\
\text { Paediatrics (STAMP) }\end{array}$ & $\begin{array}{c}\text { Paediatric patients } \\
\text { aged 2-17 years }\end{array}$ \\
\hline $\begin{array}{c}\text { Screening Tool for Risk On Nutritional status and } \\
\text { Growth(STRONGkids) }\end{array}$ & $\begin{array}{c}\text { Paediatric patients } \\
\text { aged 1 month- 16 years }\end{array}$ \\
\hline $\begin{array}{c}\text { Paediatric Yorkhill Malnutrition Score (PYMS) } \\
\text { [20] }\end{array}$ & $\begin{array}{c}\text { Paediatric patients } \\
\text { aged 1-16 years }\end{array}$ \\
\hline
\end{tabular}

SPNRS, SGNA, STAMP, STRONG, and PYMS (Table 1). Although the tools incorporate different input features, they derive similar risk categories. Generally these tools have been developed in specific situations, which may influence their applicability in other settings.

\section{Nutritional Risk Screening (NRS) Tool}

The NRS tool was primarily developed within adult populations, although 26 children were included in its initial evaluation $[13,14]$. Recently this tool was further evaluated in an Australian setting [5]. One hundred and fifty-seven children were assessed in a tertiary paediatric hospital with baseline anthropometry and completion of the NRS score. In this cohort $11.4 \%$ of paediatric patients were under-nourished and $25 \%$ were either overweight or obese at admission to hospital. Both results were similar to the result of a previous Australian study of hospitalised children [15]. In this study, $38.7 \%$ of the children who were recognised as under-nourished had a longer hospital stay. Although developed primarily for adult patients, the performance of this tool in identifying at risk paediatric patients appears acceptable.

\section{Simple Paediatric Nutritional Risk Score (SPNRS)}

In 1997 Sermet-Gaudelus and colleagues [8] established the SPNRS in a group of 296 hospitalised French children who were more than 1 month old and hospitalised for more than 48 hours. The SPNRS was based upon the patient's poor food intake $(<50 \%$ of daily diet allowance), severity of their pain and disease (pathologic conditions were graded) and classified patients as mild, moderate or high risk for nutritional deterioration. The moderate or high risk groups were then considered for dietetic interventions.
In this study a weight loss $>2 \%$ of the admission weight was chosen as an end point criterion because it was believed this much weight loss in a relatively short period of time had great prognostic significance for malnutrition. Indeed, $45 \%$ of the children lost at least this amount of weight. This tool needs two days to assess patient's nutritional risk score as the nutritional intake has to be recorded during the first 48 hours of admission, making the tool time consuming and harder to apply. On the other hand, in this study, patients' weight was the only anthropometric index taken to determine patient's current nutritional status, which could miss stunted patients. There are no published data of the subsequent evaluation of this tool in other populations.

\section{Subjective Global Nutritional Assessment (SGNA)}

In 2003 Seeker and Jeejeebhoy [3] assessed a new screening tool called SGNA at the Hospital for Sick Children, Toronto, Canada. One hundred and seventy five children, aged 1 month to 17.9 years, who were admitted for a major surgical procedure were enrolled. The SGNA comprises both subjective (e.g. growth pattern) and objective (e.g. weight) components. Based on all the information collected, children are then classified as well-nourished, moderately malnourished, or severely malnourished.

Given that the SGNA involves a detailed questionnaire and complete physical examination, as well as multiple objective measures, the completion of this tool is lengthy and hard to apply for all patients. The objective part of this tool requires anthropometric measurements and laboratory tests (for measurement of nutritional proteins), which also makes the tool timeconsuming and expensive. 
Gerasimidis et al. [16] applied SGNA along with a second tool (PYMS, see below) to 247 inpatients in UK. In their study, although SGNA showed a high specificity and positive predictive value, its sensitivity was low. Overall, this tool seems to be more of an assessment tool rather than a screening one, thereby identifying children with established malnutrition rather than "at risk" children.

\section{Screening Tool for the Assessment of Malnutrition in Paediatrics (STAMP)}

The next introduction of a new NRS tool for hospitalised children was undertaken by McCarthy et al. [17]. British children aged 2-17 years who were admitted to medical and surgical wards during a fourweek period were assessed. A subgroup of 89 children underwent a full nutritional evaluation by a registered dietitian. The STAMP tool considered three elements: clinical diagnosis of the patient and its nutritional implication (if any), nutritional intake, and anthropometric measurements. Based upon the scores from these components, each patient was classified as low, moderate or high risk for developing malnutrition. This tool contains objective parameters, but has been described more as a guide for intervention than identifying the risk of subsequent nutritional compromise.

The STAMP tool has been assessed in only one study including 89 children (with reporting in abstract form only) [16]. Of this group, $20 \%$ were classified as being at nutritional risk. This tool has been introduced into standard practice in some centres in the UK [18]. At present, an interventional study is underway in Israel to validate STAMP and identify its effect on the awareness of medical staff [19]. There are not yet reports of the utility of this tool in the clinical arena, and this tool has not yet been assessed in other settings.

\section{Screening Tool for Risk On Nutritional Status and Growth (STRONGkids)}

In 2007 a nationwide study in The Netherlands was performed in 44 hospitals over 3 consecutive days and 424 patients aged $\geq 30$ days and hospitalised $>1$ day were included [20]. The tool was called STRONGkids consisted of a questionnaire about current nutritional status of patients, existence of underlying diseases, nutritional intakes and losses and history of recent weight loss. According to the points from each aspect, children were classified as low, medium or high risk. On admission all children had their height and weight measured and assessed to see if they had acute or chronic malnutrition. By comparing the results obtained from the tool and the child's current nutritional status, they concluded that those children with higher risk scores had higher prevalence of having an underlying disease and being acutely malnourished and having longer hospital stay [20].

Since January 2008, the Dutch government has required all hospitals to screen paediatric patients for malnutrition on admission using the STRONGkids tool [11]. Although the score utilises several objective criteria, it also includes a subjective component, which may limit its broad applicability. The fact that it does not require anthropometric measurements potentially makes it faster and easier to apply.

Ling et al. [18] applied STRONGkids and STAMP to 43 British patients admitted to a paediatric hospital. They concluded that STRONGkids was more closely correlated with anthropometric indexes whilst STAMP included more children who did not need nutritional intervention in its high risk group. These authors suggested that STRONGkids is a more useful and reliable screening tool for paediatric patients.

\section{Paediatric Yorkhill Malnutrition Score (PYMS)}

The PYMS tool was introduced in UK in 2008 [16]. This tool was developed with three components: patient's current nutritional state (by measuring patient's BMI), the recent changes to nutritional status and the possibility of deterioration of patient's status as a result of their current disease. Two hundred and forty-seven children aged 1 to 16 years were studied over a four-month period in two paediatric hospitals. Patients with total score of zero were considered as low or no risk, and total scores of 1, 2 or higher were classified as moderate or high risk, respectively. The accuracy of the tool was assessed by two research dietitian who compared the nursing screening results with the full dietetic assessment, anthropometry and body composition measurements.

Although, previous studies have indicated patients with underlying disease are at greater risk of developing under-nutrition [1], this tool did not include a specific question regarding previous underlying disease or chronic conditions. This tool has not yet been evaluated in comparative settings in the UK or European setting. However, following the initial pilot study, this tool has been in routine use in a tertiary paediatric hospital and a district general hospital in the 
UK [21]. There are not yet other published reports regarding the application of this NRS tool as a routine procedure.

\section{USE OF PAEDIATRIC NRS TOOLS IN DEVELOPING COUNTRIES}

All the paediatric NRS tools mentioned above have been developed in a developed country hospital setting. Given the differences between nutritional status between developing and developed countries, the applicability of these tools in the developing setting may vary substantially.

A recent study applied three of the above tools (STRONGkids, STAMP and PYMS) to 119 children admitted to a tertiary children's hospital in Iran [22]. This report indicated that all three tools were able to identify children at nutritional risk but with differing utility. The PYMS tool classified the greatest number of children at high risk for nutritional deterioration, while it failed to recognise three malnourished children. STRONGkids appeared to have a superior correlation with anthropometric indexes and was easier to apply with no need for measuring weight and height. STRONGkids was able to detect the highest number of under-nourished patients $(16 / 30,53 \%)$ in its moderate to high risk groups, compared to $30 \%$ with the PYMS and $46 \%$ with the STAMP tools. This study also showed there was a good relationship between the risk stratification provided by all three tools and patient's duration of admission. Overall, STRONGkids was the most useful and reliable tool in that setting.

\section{CONCLUSIONS}

Evaluation of the nutritional status of paediatric patients is an essential step in clinical assessment and management. Desirable characteristics for a screening tool include being easy and quick to administer, reliable and consistent, with low false positive or false negative findings.

As detailed above, all the currently available paediatric NRS tools were initially developed and applied in European countries. These tools have recently been considered in other developed countries or in developing countries. Overall, these tools clearly have potential roles in detecting those children at risk of nutritional deterioration and enhancing clinicians' awareness of the importance of the nutritional status of paediatric patients. None has yet been accepted as a universal or ideal tool. Consequently, further studies in different settings around the world are required to more fully establish which NRS should be used in various settings.

\section{REFERENCES}

[1] Pawellek I, Dokoupil K, Koletzko B. Prevalence of malnutrition in paediatric hospital patients. Clin Nutr 2008 27: $72-76$.

http://dx.doi.org/10.1016/j.clnu.2007.11.001

[2] O'Connor J, Youde LS, Allen JR, Hanson RM, and Baur LA Outcomes of a nutrition audit in a tertiary paediatric hospital: implications for service improvement. J Paediatr Child Health 2004; 40: 295-8.

http://dx.doi.org/10.1111/j.1440-1754.2004.00367.x

[3] Secker DJ, Jeejeebhoy KN. Subjective Global Nutritional Assessment for children. Am J Clin Nutr 2007; 85: 1083-9.

[4] Duggan C, Watkins JB, Walker A. Nutrition in pediatrics: basic science. Clin Appl 2008: BC Decker Inc.

[5] Aurangzeb B, Whitten KE, Harrison B, et al. Prevalence of malnutrition and risk of under-nutrition in hospitalized children. Clin Nutr 2011; 31: 35-40. http://dx.doi.org/10.1016/j.clnu.2011.08.011

[6] Joosten K, Hulst J. Prevalence of malnutrition in pediatric hospital patients. Curr Opin Pediatr 2008; 20: 590-96. http://dx.doi.org/10.1097/MOP.0b013e32830c6ede

[7] Tienboon P. Nutrition problems of hospitalised children in a developing country: Thailand. Asia Pac J Clin Nutr 2002; 11: 258-62.

http://dx.doi.org/10.1046/j.1440-6047.2002.00307.x

[8] Sermet-Gaudelus I, Poisson-Salomon A, Colomb V, et al. Simple pediatric nutritional risk score to identify children at risk of malnutrition. Am J Clin Nutr 2000; 72: 64-70.

[9] Rocha GA, Rocha EJM, Martins CV. The effects of hospitalization on the nutritional status of children. $J$ de Pediatria 2006; 82: 70-74.

http://dx.doi.org/10.2223/JPED.1440

[10] Aurangzeb B, Whitten KE, Harrison B, et al. Prevalence of malnutrition and risk of undernutrition in hospitalised children. Clin Nutr 2012; 31: 35-40.

http://dx.doi.org/10.1016/..clnu.2011.08.011

[11] Joosten KF, Zwart H, Hop WC, Hulst JM. National malnutrition screening days in hospitalised children in The Netherlands. Arch Dis Child 2010; 95: 141-45. http://dx.doi.org/10.1136/adc.2008.157255

[12] Larsson J, Unosson AC, Nilson L, Thorslund S, Bjurulj P. Effects of dietary supplement on nutritional status and clinical outcome in 501 geriatric patients - a randomized study. Clin Nutr 1990; 9: 179-84. http://dx.doi.org/10.1016/0261-5614(90)90017-M

[13] Reilly HM, Martineau JK, Moran A, Kennedy H. Nutritional screening: evaluation and implentation of a simple nutiritiona risk score. Clin Nutr 1995; 14: 269-73.

http://dx.doi.org/10.1016/S0261-5614(95)80063-8

[14] Reilly HM. Screening for nutritional risk. Proc Nutr Soc 1996; 55: 841-53

http://dx.doi.org/10.1079/PNS19960083

[15] O'Connor J, Youde LS, Allen JR, Baur LA. Obesity and under-nutrition in a tertiary paediatric hospital. J Paediatr Child Health 2004; 40: 299-304. http://dx.doi.org/10.1111/j.1440-1754.2004.00368.x

[16] Gerasimidis K, Keane O, Macleod I, Flynn DM, Wright CM. A four-stage evaluation of the Paediatric Yorkhill Malnutrition Score in a tertiary paediatric hospital and a district general hospital. Br J Nutr 2010; 104: 751-56.

http://dx.doi.org/10.1017/S0007114510001121 
[17] McCarthy $\mathrm{H}$, McNulty $\mathrm{H}$, Dixon $\mathrm{M}$, Eaton-Evans $M J$. Screening for nutrition risk in children: the validation of a new tool. J Hum Nutr Diet 2008; 21: 395-96. http://dx.doi.org/10.1111/j.1365-277X.2008.00881 31.x

[18] Ling RE, Hedges V, Sullivan PB. Nutritional risk in hospitalised children: An assessment of two instruments. e-SPEN 2011; 6: 153-7.

[19] Clinical Trials. [homepage on the internet] Validation of a STAMP in Hospitalized Children and the Effect of Its Use on the Awareness of the Medical Staff. Updated 2012 March 28; Cited 2012 July 24; Available from: http://clinicaltrials.gov/ct2/show/NCT01563393
[20] Hulst JM, Zwart H, Hop WC, Joosten KFM. Dutch national survey to test the STRONGkids nutritional risk screening tool in hospitalized children. Clin Nutr 2010; 29: 106-11. http://dx.doi.org/10.1016/j.clnu.2009.07.006

[21] Gerasimidis K, Macleod I, Maclean A, et al. Performance of the novel Paediatric Yorkhill Malnutrition Score (PYMS) in hospital practice. Clin Nutr 2011; 30: 430-5. http://dx.doi.org/10.1016/j.clnu.2011.01.015

[22] Moeeni V, Walls T, Day AS. Assessment of nutritional status and nutritional risk in hospitalised Iranian children. Acta Paediatr 2012; 101: e446-51.

http://dx.doi.org/10.1111/j.1651-2227.2012.02789.x 